Looking back at the first 2 years...

\section{Early results suggest sterile flies may protect S. California from medfly}

\author{
Robert V. Dowell \\ Isi A. Siddiqui \\ J Fred Meyer \\ E. Leon Spaugy
}

\begin{abstract}
Sterile medflies are being released at a weekly rate of 125,000 to 200,000 flies per week per square mile over a 2,155-squaremile area of urban Southern California to help prevent the development of new medfly infestations. This areawide approach reduced the annual number of infestations found from 1994 to 1998 in the treated area by $93.3 \%$, compared to infestations detected between 1987 and 1993.
\end{abstract}

No exotic insect raises as much concern among regulatory officials at the California Department of Food and Agriculture (CDFA), the U.S. Department of Agriculture (USDA) and the California County Agricultural Commissioners (CAC) as the detection of a Mediterranean fruit fly (medfly). This concern is based on the economic and environmental damage the medfly could cause if it became established statewide.

In a worst-case scenario, assuming medfly becomes a permanent resident statewide, scientists have estimated direct crop losses due to larval infested fruit would be as high as $\$ 210$ million per year. They expect California growers would use an extra 1.4 million pounds of pesticide active ingredient (ai) annually to prevent the medfly from infesting fruits and vegetables. This increased pesticide use would result in secondary pest outbreaks that would themselves require an estimated additional 9,000 pounds ai of pesticides annually. Total cost of these pesticide treatments is estimated at up to $\$ 732$ million per year (CDFA 1994).
Forty-two countries including China, Japan and Taiwan, have quarantine laws designed to prevent the movement of medfly-infested commodities into their countries (CDFA 1994). A permanent medfly (Ceratitis capitata) presence in California would require postharvest treatment of affected fruit. Postharvest treatment, including methyl bromide fumigation or cold treatment, could cost \$564 million with treatment-induced crop losses of up to $\$ 80$ million. Quarantine compliance alone could cause the loss of up to 14,000 jobs (Siebert and Cooper 1995).

The effects of a permanent, statewide medfly presence are not limited to commercial agriculture. It is estimated that homeowners would increase their pesticide use by 346,000 pounds ai per year at a cost of $\$ 5 \mathrm{mil}$ lion. Crop losses to dooryard produce could be as high as 212 million pounds each year with a replacement cost of $\$ 127$ million (CDFA 1994).

\section{Medfly in L.A. Basin, 1987-1993}

Until 1994, the CDFA/USDA/CAC had a reactive strategy for dealing with medfly infestations in California. Eradicative treatments were begun only after finding and delimiting an existing medfly infestation. By late 1993, it had become obvious that this reactive approach was not effectively dealing with the medfly infestations being found in the Los Angeles Basin. Medfly infestations had been found each year since 1987 . The number of wild medflies detected each year decreased only after a large aerial Malathion and bait spray program in
1989-1990. During 1993, 400 wild medfly adults were trapped in 39 cities in five Southern California counties. These finds represented 35 discrete core infestations whose treatment boundaries were merging into another large infested area like that seen in 1989-1990 (Dowell and Penrose 1995; Penrose 1996).

\section{4: Basinwide program begins}

Based on advice from international medfly experts (including authorities from the International Atomic Energy Agency in Austria), the CDFA/ USDA/CAC on March 1, 1994, began a basinwide sterile release program designed to eradicate the medfly in Southern California. The success of this program, lasting 2 years and 4 months, led to its continuation in a larger square-mile area, using different rates of sterile medfly release and trapping beginning July 1996 . The latter Medfly Preventative Release Program was established for 5 years, to be evaluated for its costs and benefits in July 2001.

The goal of a sterile medfly release program is to provide a sufficient number of sterile male medflies in the environment to ensure that any unmated wild female medflies present will mate with a sterile male and so produce infertile eggs. The mass rearing process and subsequent sterilization by exposure to gamma radiation reduces the mating competitiveness of the sterile medflies. To compensate for this reduced mating competitiveness, the "rule of thumb" has been to have at least 100 sterile male medflies present in the environment for every wild medfly.

To enhance the effectiveness of the sterile medflies, pesticide sprays are applied first to reduce the population of wild medflies and to kill any fertile wild medfly females that might be present (Dowell and Penrose 1995).

The first use of sterile medflies in California was in 1976-1977. Since then they have been used in a number of programs in California (Penrose 1996; Dowell and Penrose 1995; Penrose 1993). They have also been used successfully in Argentina (Aruani et al. 1996), Peru and Chile 


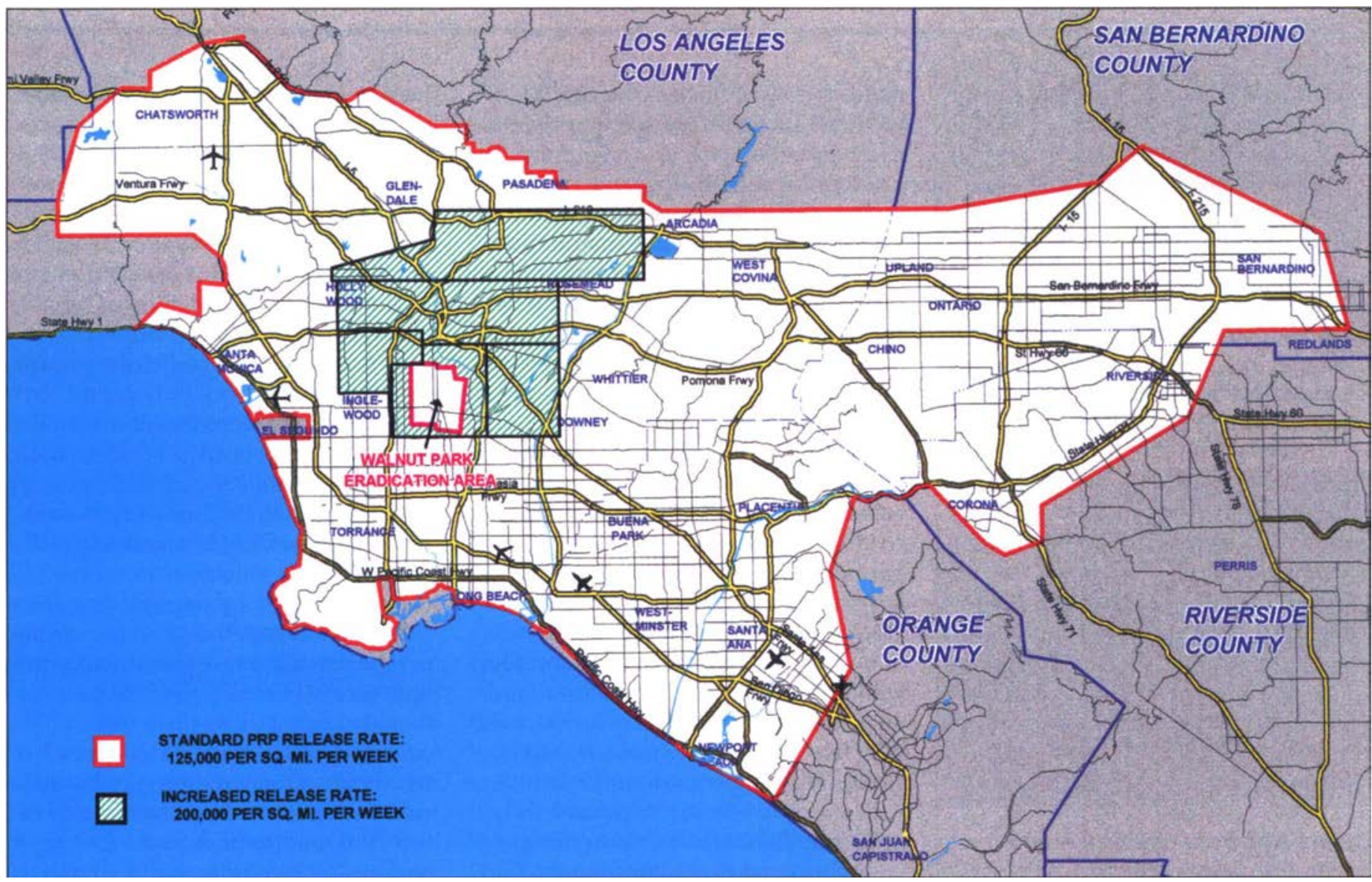

Fig. 1. Boundaries of the Mediterranean fruit fly preventative release program (PRP), the PRP area now receiving the increased application rate of 200,000 sterile medflies per week, and the Walnut Park eradication area.

(Ocampo, personal communication), Guatemala (Villasenor, pers. comm.), Mexico (Schwarz et al. 1989) and Florida (Knapp, pers. comm.). Most of these programs reactively used sterile flies to eradicate infestations. The 1994-1996 basinwide programs, and the PRP that followed, were designed to eradicate all extant medfly present and to prevent new infestations from becoming established (Dowell and Penrose 1995).

California's sterile medfly programs initially used a mixture of male and female medflies, all sterilized by radiation at facilities in Guatemala and Hawaii. Recent work in Hawaii (McInnis et al. 1994) and Guatemala (Rendon, pers. comm.) suggests that releases of predominantly sterile male medflies are more effective at producing sterile eggs in populations of wild medflies than the releases of both sterile males and females.

Predominantly male medfly populations, also known as temperature sensitive lethal (TSL) populations, are now used against infestations outside
PRP to effect eradication. These TSL medflies have a gene inserted into the chromosome that selectively kills females exposed to high temperatures. Medfly eggs are collected and heated in a water bath to kill most of the females prior to rearing. This results in TSL populations that are over $95 \%$ sterile male medflies. CDFA and USDA are taking steps to convert the rearing facilities in Hawaii to rearing TSL flies for use in the PRP.

The boundaries of the initial basinwide program of 1994-1996 were drawn to include all existing medfly infestations and areas where medfly infestations had been eradicated in the previous 7 years - a 1,464-squaremile area.

Malathion and bait were applied to all hosts within a 660 -foot radius of each 1994 fly find to kill any fertile female medflies present. Next, we began continuous releases of 250,000 sterile medflies per square mile per week (medflies $/ \mathrm{mi}^{2} / \mathrm{wk}$ ). The release rate was the upper limit of that used in Mexico's successful medfly eradica- tion/exclusion program (Schwarz et al. 1989).

The capture of wild medflies within the basinwide treatment boundaries dropped from 400 in 1993 to 7 in 1994 , and finally to no wild medflies in 1995. This reduction was partly the result of a reduction in delimitation trap density, and partly the result of the sterile fly program. Delimitation traps for a period of time numbered $1,000 / \mathrm{mi}^{2}$ and were subsequently reduced to $100 / \mathrm{mi}^{2}$ in the core square mile. Only one wild fly was trapped within the basinwide area in 1996 and it was an unusually desiccated male medfly that was trapped in Burbank the day after the basinwide program had ended.

\section{PRP launched in 1996}

Based on the success of the basinwide program and advice from the Medfly Science Advisory Panel, the CDFA/USDA/CAC started a new Medfly Preventative Release Program (PRP) over a 2,155-square-mile area of Southern California on July 10, 1996 (fig. 1). The PRP covered the area in- 
cluded in the 1994-1996 basinwide program and an additional 691 square miles in Riverside, San Bernardino, and Orange counties (fig. 1). Boundaries encompassed all previous medfly infestations in the Los Angeles Basin and as much of the adjacent contiguous urban area as allowed with the available supply of sterile medflies. Under the PRP, and in accordance with MEDSAP recommendations, the sterile medfly releases were reduced to a minimum of 125,000 sterile medflies $/ \mathrm{mi}^{2} / \mathrm{wk}$. Detection trapping density was set at five McPhail and five Trimedlurebaited Jackson traps $/ \mathrm{mi}^{2}$, the latter reduced from 10 previously.

Medfly infestations found outside the PRP were to be treated with the preferred reactive approach of the CDFA/USDA/CAC: ground-applied Malathion and bait sprays followed by the release of sterile medflies.

The PRP itself costs approximately $\$ 13$ million per year with the cost shared equally by the CDFA and USDA. Five years after its July 10, 1996, starting date, we will evaluate the PRP, including its costs and benefits, and any medfly infestations found within its borders.

As a joint CDFA/USDA/CAC effort, the PRP is reviewed annually by a Medfly Science Advisory Panel (MEDSAP), comprised of Derrell Chambens (Chair) (USDA retired), Eric Jang (USDA), Richard Rice (University of California), Jorge Hendrichs (International Atomic Energy Agency, Vienna, Austria) and Aldo Malavasi (University of Sao Paulo, Sao Paulo, Brazil). MEDSAP members all have extensive experience with the medfly.

The PRP has five chief components.

Sterile fly release. Sterile medflies for the PRP are supplied by the CDFA and USDA medfly rearing facilities in Hawaii and from a sterile medfly rearing facility in Guatemala. The sterile fly pupal emergence facility at Los Alamitos (in Orange County, Calif.) incubates and emerges 450 million sterile medfly pupae weekly and evenly disperses the sterile adult flies over the PRP. Prior to release, the flies from each rearing facility are mixed to prevent any part of the PRP continually receiving flies from a single ge- netic stock. This lowers the risk of wild female flies developing resistance to a particular stock of sterile males (McInnis et al. 1996).

One population of wild medflies in Hawaii has been found to actively discriminate against sterile medflies reared in Hawaii. This population of wild flies was in a small planting of coffee and had been subjected to continuous, noneradicative releases of sterile flies for a number of generations with continual immigration of wild medflies from the surrounding areas. The population showed no discrimination in mating when tested against sterile medflies from other mass rearing colonies (McInnis et al. 1996). Tests conducted using wild medflies from eight countries and four strains of mass-reared medflies found no evidence of "resistance" in the wild medflies to any of the mass-reared strains (Cayol, pers. comm.).

The sterile flies are released 7 days per week. Releases are made along predetermined flight lines using a Global Positioning System satellite navigation guidance and recording system. The release rate is the same as the lower limit used in the successful Mexican fruit fly exclusion program, no less than 125,000 sterile medflies / $\mathrm{mi}^{2} / \mathrm{wk}$ (Schwarz et al. 1989). Twiceweekly releases of a minimum of 62,500 sterile flies $/ \mathrm{mi}^{2} / \mathrm{wk}$ are made to achieve this goal. The twice-weekly releases allow for a more even distribution of the sterile medflies. They also provide a greater average standing population of sterile medflies, which have a postrelease half-life of 4 to 5 days in California. An estimated 37 billion sterile medflies will have been released between July 10, 1996, and April 30, 1999.

Trapping. Five Trimedlure-baited Jackson traps and five McPhail traps are deployed per square mile throughout the PRP to detect the presence of wild medflies and to help project managers monitor activities. The CDFA/USDA/CAC settled on five Trimed-lure-baited Jackson traps $/ \mathrm{mi}^{2}$, based on our experiences in detecting medfly infestations in other areas of the state. Five Trimedlure-baited traps $/ \mathrm{mi}^{2}$ is half the density used in the previous basinwide program, and half the density used in high-risk urban areas of Southern California not in the PRP (CDFA 1995). It is the same density used in the general detection program in Southern California urban areas for Mexican fruit flies and others (CDFA 1995).

The Jackson traps are inspected every 2 weeks and the McPhail traps are inspected every week year-round. The total number of traps monitored in the project area is about 15,000 . Within PRP boundaries, 23 wild medflies were trapped in 1997 and 1 wild medfly was trapped in 1998. Outside PRP boundaries, 94 wild medflies were trapped in 1998 (see page 6).

Larval survey. Based on the recommendation of international medfly experts (not MEDSAP), the PRP conducted extensive larval surveys focused on areas with a high risk of medfly introduction, that is, wholesale fruit markets, fruit importers, areas of historical medfly finds and exotic fruit markets in 1996. However, such random and undirected surveys found no larvae and were discontinued in 1997. Additional fruit cutting was done in the vicinity of the wild medflies trapped in 1997 and 1998. These focused, delimitation surveys found 11 properties with medfly-infested fruit in 1997 in the PRP and no larvae within the PRP in 1998.

Fly identification. All adult medflies trapped in the Jackson and McPhail traps throughout the PRP are identified as either sterile or wild flies. Sterile medflies are marked with a fluorescent pink dye. Wild medflies do not have the dye. When an undyed fly is discovered, a trained biosystematist dissects and examines its reproductive organs to determine if it is sterile or wild. Irradiated medflies have atrophied ovaries and testes, which look different from those of unirradiated medflies. Some 350,000 to 500,000 dyed sterile medflies are examined each week with an average of five requiring dissection because they have insufficient dye to be initially identified as sterile.

The project maintains an ongoing quality-control program of the fly identification section. On average, five 
"test" flies, which are undyed yet sterile, are placed in both Jackson and McPhail traps in no set pattern each week. Recovery of the undyed medflies by identification lab staff exceeds $95 \%$.

Data management. Program managers ensure that all areas within the PRP are receiving sufficient sterile medflies, as indicated by the number of sterile medflies caught in the detection traps, and that the quality of sterile medflies received meets acceptable criteria for emergence, flight and mating propensity. Traps with less than acceptable catch of sterile flies are examined to determine if the cause is (1) poor trap placement, which is immediately corrected, (2) poor host number in the area, which leads to the sterile flies leaving and immediate trap relocation; or (3) trap tampering, which leads to immediate relocation. To date, trap catches have returned to acceptable levels when trap placement has been corrected. The sterile medfly rearing labs are given continual feedback so that they can correct any declines in fly quality.

1997 Walnut Park infestation. On Sept. 26, 1997, the first of 23 adult wild medflies found within the PRP was trapped in the Walnut Park area of Los Angeles County (fig. 1). The initial medfly find was a female caught in a McPhail trap that had been relocated into the infested area the previous week. Subsequent female and male medflies were caught in Jackson and McPhail traps put out as part of the delimitation effort.

Larval surveys found 11 properties harboring numerous medfly larvae in dooryard fruit. The PRP responded by applying ground sprays of Malathion and bait to host plants within a 660 foot radius of each property on which medfly adults or larvae were found. The host fruit from the properties on which medfly larvae were found and the adjacent properties were stripped and diazinon was sprayed on the soil under these plants.

Subsequently, the release rate of sterile medflies was increased fourfold to $500,000 \mathrm{flies} / \mathrm{mi}^{2} / \mathrm{wk}$ in a 9 -square mile area around each property on which a wild medfly was found. The eradication zone was 16 square miles (fig. 1). The increased release rate was maintained 6.5 months, from Oct. 3 , 1997, until April 16, 1998 - a time interval equal to three medfly generations based on a temperature-driven developmental model using local air and soil temperatures (CDFA 1989). Additionally, managers decided to increase the release rate of sterile flies to $250,000 / \mathrm{mi}^{2} / \mathrm{wk}$ in a 65 square-mile buffer area around the eradication zone from Oct. 3, 1997, until April 16, 1998 , to provide additional "insurance" that the medfly infestation was eradicated. This rate has now been reduced to $200,000 / \mathrm{mi}^{2} / \mathrm{wk}$.

Because there was considerable concern about a medfly infestation developing within the PRP, the CDFA/ USDA/CAC performed studies to attempt to determine whether the infestation was due to resistance of the wild flies to the sterile flies, to an operational failure such as poor fly quality or a breakdown in the delivery of the sterile medflies, an inability of the five Trimedlure-baited traps $/ \mathrm{mi}^{2}$ to detect a medfly infestation or a new introduction that was sufficiently large to overwhelm the sterile medflies and have wild males and wild females.

Medfly larvae from Walnut Park were sent to the USDA-APHIS laboratory in Hawaii. The flies were allowed to complete their life cycle and the subsequent females were tested for mating compatibility against Hawaiian strains of sterile male medflies. The wild medflies from California showed no signs of mating resistance to the sterile medfly males reared in Hawaii (Lance, pers. comm.).

The CDFA conducted a detailed analysis of the PRP in which the operational aspects of the program in the Walnut Park area were compared to those from other areas in which wild medflies were not found. We examined sterile fly quality including emergence, flight and mating propensity, time interval between sterile fly releases, trap catch of sterile flies and the results of quality control tests of the trapping program. There were no operational aspects of the program that were unique to the Walnut Park area.

The infestation was small physically, encompassing 0.6 square miles,

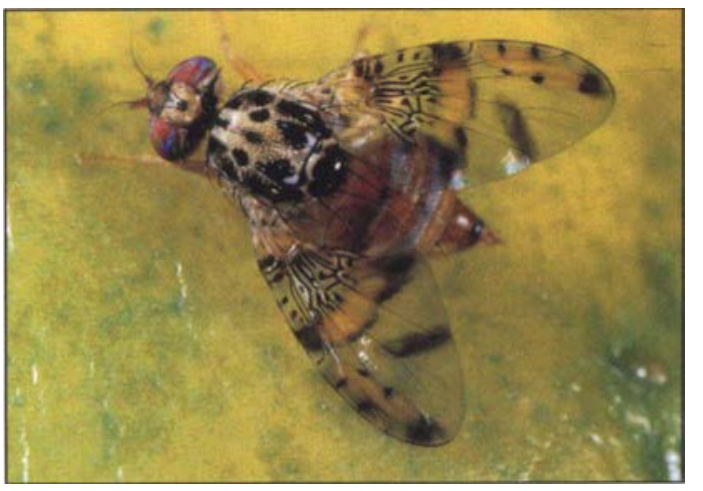

The medfly, above, lays its eggs under the skin of fruits. After hatching, its maggots feed on the pulp of the host fruit, as shown on the grapes below.

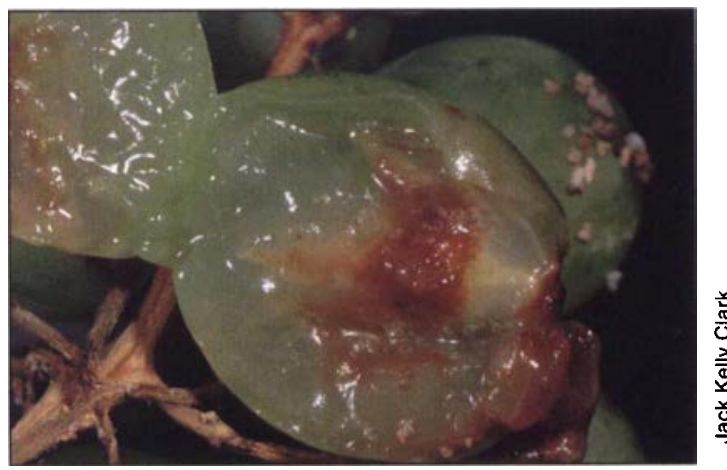

$0.03 \%$ of the PRP. This is one-fifth of the average geographic size of the infestations discovered during 1988 and 1989. These years were selected for comparison because the infestations occurred after a multiyear period free of medfly infestations similar to that from 1995 to 1996 . The small size of the infestation combined with lack of satellite infestations suggests that the Walnut Park infestation may have been new and that the sterile medflies were able to contain it (CDFA 1998).

The discovery of the Walnut Park infestation confirms that the detectiontrapping program is able to detect infestations covering a small area and that the CDFA policy of relocating traps every 6 weeks is an important component in an effective fruit fly detection program.

Nuclear DNA analysis of the Walnut Park medflies (which may differentiate among multiple introductions from the same area) found bands not seen in wild medflies from previous infestations in Southern California, suggesting that the Walnut Park infestation may have represented a new introduction (D. Haymer, unpublished data). Analysis on mitochondrial DNA (mtDNA) of the Walnut Park flies 
found the same pattern previously found in the majority of flies from Southern California indicating their origin was Central America or the Mediterranean. At present, mtDNA cannot differentiate among multiple introductions of flies from the same geographic area. (McPheron, unpublished data).

To help prevent another Walnut Park-type infestation, we increased the release rate of sterile medflies to at least $200,000 \mathrm{flies} / \mathrm{mi}^{2} / \mathrm{wk}$ in a 250 square-mile area of the PRP (fig. 1).

$\mathbf{1 9 9 8}$ wild medfly in PRP. On Nov. 19, 1998, a single mated wild female medfly was trapped in the Santa Ana PRP area of Orange County. Because the fly was dead, it was not possible to determine if she had mated with a sterile or wild male, and therefore whether or not this was an infestation. Subsequent delimitation trapping and fruit cutting did not uncover any additional wild medflies in this part of the PRP. Occasional detection of a single wild medfly within the PRP was expected. The PRP is designed to prevent successful medfly breeding. If infested fruit is being brought into the PRP, there are no actions being taken to prevent the introduced maggots from completing their development and the subsequent adults from being caught in our detection traps.

The MEDSAP noted a number of facts that indicate that medfly-infested fruit is being brought into the PRP area. The most obvious are the discovery of the Walnut Park infestation in 1997 and the capture of the medfly in Santa Ana in 1998. The discovery of medfly infestations outside the PRP in 1998 also indicate that medfly-infested produce is entering Southern California and it stretches credibility to assume that it all is going to sites outside the PRP. Lastly, the discovery of the olive fruit fly within the PRP is important because the olive fruit fly and medfly occupy the same geographical area throughout the range of the olive fruit fly. If olive fruit fly-infested fruit is entering California, it is likely that medfly-infested fruit from the same area is also entering. The absence of known medfly infestations within the PRP area in 1998 is an indication that sterile medfly releases are an effective colonization barrier (CDFA 1998).

\section{Lessons from Walnut Park}

The Walnut Park infestation demonstrates that the release of 125,000 sterile medflies $/ \mathrm{mi}^{2} / \mathrm{wk}$ alone can reduce but cannot stop the development of new infestations that arise from new introductions of medfly-infested plant material. The CDFA/USDA/ CAC must continue to increase their efforts to identify and close the pathways through which illegal fruit is entering the state.

The PRP and its predecessor, the basinwide program, have reduced the rate of detection of wild medflies from an average of 126.0 per year from 1987 to 1994 to 6.0 from 1995 to 1998 , a $95 \%$ reduction. Although the number of medflies caught in 1992-1993 was increased by the experimental use of up to 1,000 Trimedlure-baited yellow panel traps $/ \mathrm{mi}^{2}$ in delimitation activities in the core square mile, the majority of the decrease from 1987 to 1993 compared to 1994 to 1998 is due to fewer wild medflies present to be caught due to the basinwide program and the PRP preventing medfly reproduction in the area. (Trap finds outside the PRP, such as those at Lake Elsinore in 1998, are not included in these figures. See page 6.)

More importantly, the number of infestations has decreased from an average of 7.5 per year from 1987 through 1993 to 0.50 per year from 1994 through 1998, a $93.3 \%$ reduction. Using large-scale releases of sterile medflies has resulted in a substantial reduction in the rate at which wild medfly adults are being trapped in the greater Los Angeles area and an equally large reduction in the development of new medfly infestations.

An annual report covering PRP activities is prepared for the legislature by the CDFA. Copies can be obtained by writing to the Pest Detection/ Emergency Projects Branch, California Department of Food and Agriculture, 1220 N Street, Sacramento, Calif. 95814.

R.V. Dowell is Primary State Entomologist of California Department of Food and Agriculture (CDFA) and a Lecturer, De- partment of Entomology, UC Davis; I.A. Siddiqui is Special Assistant for Trade to Secretary of U.S. Department of Agriculture; F. Meyer was an Area Manager, CDFA; and E.L. Spangy is the retired Los Angeles County Agricultural Commissioner.

\section{References}

Aruani R, Ceresa A, Granados JC, Taret G, Peruzzotti P, Ortiz G. 1996. Advances in the national fruit fly control and eradication program in Argentina. p 521-30. In, McPheron BA, Steck GJ (eds.) Fruit Fly Pests A World Assessment of their Biology and Management. St. Lucie press, Delray Beach Florida..

California Department of Food and Agriculture. 1994. Final programmatic environmental impact report. The exotic fruit fly eradication program using aerial application of Malathion and bait. Clearinghouse number 91043018

California Department of Food and Agriculture. 1995. Insect Trapping Guide. Gilbert $J$, Bingham RR (eds.).

California Department of Food and Agriculture. 1989. Mediterranean fruit fly eradication action plan.

California Department of Food and Agriculture. 1998. Mediterranean fruit fly preventative release program. Report to the Legislature.

Dowell RV, Penrose R. 1995. Mediterranean fruit fly eradication in California 19941995. In, Morse JG, Metcalf RL, Carey JR, Dowell RV (eds.) The Mediterranean fruit fly in California: defining critical research. Coll Natur and Agric Sci. Univ Calif Riverside. p 161-85.

McInnis DO, Lance DR, Jackson CG. 1996. Behavioral resistance to the sterile insect technique by Mediterranean fruit fly (Diptera: Tephritidae) in Hawaii. Ann Entomol Soc Am 89:739-44.

McInnis DO, Tam S, Grace C, Miyashita D. 1994. Population suppression and sterility rates induced by variable sex ratio, sterile insect releases of Ceratitis capitata (Diptera: Tephritidae) in Hawaii. Ann Entomol Soc Amer 87: 231-40.

Penrose R. 1993. The 1989/1990 Mediterranean fruit fly eradication program in California. Pages 401-6. In, Aluja M, Liedo P (eds.) Fruit Flies Biology and Management. Springer-Verlag.

Penrose D. 1995. California's 1993/1994 Mediterranean fruit fly eradication program In, McPheron BA, Steck GJ (eds.) Fruit fly pests. A world assessment of their biology and management. St. Lucie Press, Delray Beach, Florida. p 551-4.

Schwarz AJ, Liedo JP, Hendrichs JP. 1989. Current programme in Mexico. In, Robinson AS, Hooper G (eds.) World Crop Pests. Fruit flies Their biology, natural enemies and control. Volume 3B. Elsevier. Chapter 9.5 .3

Siebert JB, Cooper T. 1995. Embargo on California produce would cause revenue, job loss. Cal Ag 49(4): 7-12. 